\title{
Structural Changes between Seasons in the Songbird Auditory Forebrain
}

\author{
Geert De Groof, ${ }^{1}$ Marleen Verhoye, ${ }^{1,2}$ Colline Poirier, ${ }^{1}$ Alexander Leemans, ${ }^{3}$ Marcel Eens, ${ }^{4}$ Veerle M. Darras, ${ }^{5}$ \\ and Annemie Van der Linden ${ }^{1}$ \\ ${ }^{1}$ Bio-Imaging Laboratory, University of Antwerp, B-2020 Antwerp, Belgium, ${ }^{2}$ Vision Laboratory, University of Antwerp, B-2610 Wilrijk (Antwerp), \\ Belgium, ${ }^{3}$ Image Sciences Institute, Department of Radiology, University Medical Center Utrecht, 3584 CX Utrecht, The Netherlands, ${ }^{4}$ Ethology Research \\ Group, Department of Biology, University of Antwerp, B-2610 Wilrijk, Belgium, and ${ }^{5}$ Animal Physiology and Neurobiology Section, Katholieke Universiteit \\ Leuven, B-3000 Leuven, Belgium
}

The song control system (SCS) of seasonal songbirds shows remarkable seasonal plasticity. Male starlings (Sturnus vulgaris) sing throughout the year, but in the breeding season, when concentrations of testosterone are elevated, the song is highly sexually motivated. The main goal of this study was to investigate structural seasonal changes in regions involved in auditory processing and in socio-sexual behavior. Using in vivo Diffusion Tensor Imaging (DTI), we measured in breeding and nonbreeding seasons volume and tissue characteristics of several brain regions of nine adult male starlings. We demonstrate that the songbird brain exhibits an extreme seasonal plasticity not merely limited to the SCS. Volumetric analysis showed seasonal telencephalon volume changes and more importantly also a volumetric change in the caudal region of the nidopallium (NCM), a region analogous to the mammalian secondary auditory cortex. Analysis of the DTI data allowed detection of seasonal changes in cellular attributes in NCM and regions involved in social behavior. This study extends our view on a seasonally dynamic avian brain which not only hones its song control system but also auditory and social systems to be prepared for the breeding season.

\section{Introduction}

Song production by adult male songbirds can be used to attract mates and defend territories (Eens, 1997). European starlings (Sturnus vulgaris) are a typical example of songbirds, in which song production and the factors that motivate it differ seasonally. Male starlings sing throughout the year, but during the breeding season (spring), when concentration of plasma testosterone $(\mathrm{T})$ is elevated, singing behavior can be highly sexually motivated (Riters et al., 2000). In the nonbreeding season, when plasma concentration of T is basal (Ball and Wingfield, 1987; Riters et al., 2002), song rather plays a role in social interactions such as maintenance of cohesion and of dominance hierarchies within the flock (Summers et al., 1987; Hausberger et al., 1995; Eens, 1997). As such, male European starlings are an ideal model system to explore seasonal neural plasticity of singing behavior.

The "social behavior network" (SBN), an interconnected group of structures in the mammalian brain, controls multiple social behaviors including aggression and courtship (Newman,

Received April 14, 2009; revised Aug. 31, 2009; accepted Sept. 28, 2009.

This research was supported by Concerted Research Actions (GOA funding) from the University of Antwerp, Inter University Attraction Poles (IUAP-NIMI-P6/38) to A.V.d.L. and grants from Fonds voor Wetenschappelijk Onderzoek (FW0)-Flanders (FW0, Project Nr. G.0420.02) to V.D., M.E., and A.V.d.L. G.D.G. was supported by a Ph.D. fellowship of FWO-Flanders. This research was partly sponsored by European Network of Excellence (NoE) European Molecular Imaging Labs (LSHC-CT-2004-503569) and NoE Diagnostic Molecular Imaging (LSHB-CT-2005-512146). We thank the three anonymous reviewers for their helpful comments on this manuscript.

Correspondence should be addressed to Geert De Groof, Bio-Imaging Laboratory, University of Antwerp, CGB, Groenenborgerlaan 171, B-2020 Antwerp, Belgium. E-mail: Geert.DeGroof@ua.ac.be.

DOI:10.1523/JNEUROSCI.1788-09.2009

Copyright $\odot 2009$ Society for Neuroscience ～0270-6474/09/2913557-09\$15.00/0
1999). In songbirds, homologues for these regions have been identified (Goodson, 2005) and are implicated in the regulation of singing behavior (Riters and Ball, 1999; Maney and Ball, 2003; Heimovics et al., 2009). More and more studies suggest that the SBN differentially regulates song production within and outside the breeding season (Heimovics and Riters, 2007). In seasonal breeding songbirds, gonadal steroids increase SBN immediate early gene (IEG) expression induced by a socio-sexual signal (Maney et al., 2008). Furthermore, gonadal steroids appear to increase the salience of socio-sexual signals acting through auditory, visual or olfactory systems (Hultcrantz et al., 2006). For instance, the avian forebrain analog of the secondary auditory cortex is selective for song over tones only when plasma steroids exceed nonbreeding levels in a female seasonal songbird (Maney et al., 2006).

Diffusion tensor imaging (DTI) is a noninvasive technique that allows repeated measures on the same individuals across seasons. Taking advantage of this technique, we recently demonstrated significant seasonal changes in white matter structures of the starling brain (De Groof et al., 2008). Despite the abundant use of DTI in investigating brain white matter changes, its use in investigating gray matter changes is relatively recent (Bhagat and Beaulieu, 2004; Lebel et al., 2008; Pfefferbaum et al., 2008). DTI can provide quantitative data about changes in diffusivity resulting from intracellular changes (protein synthesis, vesicle formation or concentration of organelles) and extracellular changes such as dendrite branching (Pierpaoli et al., 1993; Beaulieu, 2002; Hasan et al., 2009).

The main goal of this study was to investigate potential seasonal plasticity of the SBN and auditory regions at the structural 
level. Using DTI, we thus repeatedly measured tissue characteristics and volumes of these regions in 9 adult male starlings in breeding (spring) and nonbreeding seasons (summer).

\section{Materials and Methods}

Subjects. Nine adult male European starlings (Sturnus vulgaris; $\pm 75 \mathrm{~g}$ ) were obtained from a wild-caught stock maintained in large outdoor aviaries at the Drie Eiken Campus (University of Antwerp). They were temporarily housed during the experiments in two indoor cages $(1.40 \times$ $2.20 \times 2.10 \mathrm{~m})$ under an artificial light-dark cycle reproducing the photoperiod observed at the corresponding time of the year. The experiments were conducted in spring, between 7 April and 26 April, 2004, during the breeding season and were repeated in summer, between 19 July and 2 August, 2004, during the beginning of the nonbreeding season in Belgium (i.e., when birds have become photorefractory and are no longer stimulated by long day photoperiods so that their gonads are fully regressed). Between the experiments, birds were relocated in the large outdoor aviaries at the University of Antwerp. Food and water were available ad libitum. All experimental procedures were approved by the Committee on Animal Care and Use at the University of Antwerp, Belgium.

Experimental set-up. Birds were anesthetized as described previously (Van Meir et al., 2004) with an initial intramuscular (chest) injection of 5 $\mathrm{ml} / \mathrm{kg}$ of a mixture containing $0.33 \mathrm{ml}$ of xylazine (Rompun: $20 \mathrm{mg} / \mathrm{ml}$ ), $2.10 \mathrm{ml}$ of ketamine (Ketalar: $50 \mathrm{mg} / \mathrm{ml}$ ) and $4.33 \mathrm{ml}$ of saline solution. During the whole experiment, starlings were kept anesthetized with this mixture at a rate of $0.15 \mathrm{ml} / \mathrm{h}$ through a chest catheter (Micro-Flo, 27GA, DKS Overscan), and body temperature was continuously monitored and automatically regulated within a narrow range of $40-41^{\circ} \mathrm{C}$ with a control heated warm water blanket (Kent Scientific Corporation). The bird's head position was fixed by a nonmagnetic stereotaxic beak-bar and headholder combined with a circular receive surface coil (diameter $24 \mathrm{~mm}$ ) and a transmit head coil (Helhmoltz: diameter $45 \mathrm{~mm}$ ). Imaging was performed on a $7 \mathrm{~T}$ horizontal bore MR microscope (MRRS), provided with shielded gradients $(8 \mathrm{~cm}$ width, maximal strength $=400 \mathrm{mT} / \mathrm{m}$; Magnex Scientific). Diffusion weighted spin echo images were acquired with diffusion gradients applied in 6 noncollinear directions (diffusion gradient strength $=69 \mathrm{mT} / \mathrm{m}$ for each direction, time diffusion gradient $\delta=12 \mathrm{~ms}$, interval between onsets diffusion gradients $\Delta=20 \mathrm{~ms}$, $b$ value $=788 \mathrm{~s} / \mathrm{mm}^{2}$ ) according to the Basser scheme (Basser et al., 1994). Images consisted of 24 adjacent sagittal slices (thickness $0.4 \mathrm{~mm}$ ) covering the right hemisphere of the starling brain. Additional image parameters were: field of view $(\mathrm{FOV})=25 \mathrm{~mm}$, spectral width $=25 \mathrm{kHz}$, $\mathrm{N}_{\mathrm{av}}=14$, echo time $(\mathrm{TE})=43 \mathrm{~ms}$, repetition time $(\mathrm{TR})=2200 \mathrm{~ms}$, and acquisition matrix $=256 \times 128$ zero-filled to $256 \times 256$ (in plane resolution $=0.098 \times 0.098 \mathrm{~mm}^{2}$ ). Each DTI experiment took $\sim 8.5 \mathrm{~h}$. All starlings recovered perfectly after each MR experiment.

DTI calculation was done with the "Diffusion II Toolbox" implemented in SPM (Statistical Parametric Mapping, version 5) (http://www. fil.ion.ucl.ac.uk/spm/). Diffusion-weighted images were first corrected for head movements using rigid body realignment to the $\mathrm{B}_{0}$-image. Then, the diffusion tensor was estimated for each voxel from which different invariant indices maps were calculated: mean diffusivity (MD), eigenvalues $\left(\lambda_{1}, \lambda_{2}, \lambda_{3}\right)$ and fractional anisotropy (FA) maps. FA is a measure of the directionality of the water diffusion within a given voxel and is computed on a voxel-by-voxel basis using equation (Le Bihan et al., 2001):

$\mathrm{FA}=$

$$
\sqrt{3\left[\left(\lambda_{1}-\mathrm{MD}\right)^{2}+\left(\lambda_{2}-\mathrm{MD}\right)^{2}+\left(\lambda_{3}-\mathrm{MD}\right)^{2}\right]} / \sqrt{2\left(\lambda_{1}^{2}+\lambda_{2}^{2}+\lambda_{3}^{2}\right)},
$$

with $\lambda_{1}, \lambda_{2}, \lambda_{3}$ the eigenvalues of the diffusion tensor and MD the average of the three eigenvalues.

$\mathrm{T}_{2}$ maps were calculated to provide information on the brain tissue water content. This included the acquisition of two Spin Echo (SE) experiments with different echo time $\left(\mathrm{TE}_{1}=18 \mathrm{~ms}, \mathrm{TE}_{2}=56 \mathrm{~ms}\right)$ at the same position and orientation as the DTI images. Other image parameters were: (FOV: $25 \mathrm{~mm}$; 24 sagittal slices covering the right hemisphere; slice thickness: $0.4 \mathrm{~mm}$; acquisition matrix: $256 \times 128$; $\mathrm{TR}=2000 \mathrm{~ms}, 10$ averages). The calculation of quantitative $\mathrm{T}_{2}$-maps in which the gray level of each pixel represents the fit-parameter $T_{2}$ was performed using in-house software developed in IDL (Interactive Data Language).

Beak color. The beak color of all subjects was assessed both in spring and summer. Beak color in European starlings is dependent on plasma T (Dawson, 1983; Ball and Wingfield, 1987), changing from black in summer (when plasma T levels are basal) to yellow in spring (when plasma $\mathrm{T}$ levels are higher). It was recorded on an arbitrary scale of 0 (bill entirely black, from base to tip) to 5 (bill entirely yellow) (De Ridder et al., 2002).

Testosterone assay. Each season, after magnetic resonance imaging (MRI) testing, blood samples were taken from each male to assay $\mathrm{T}$ concentrations. The alar wing vein was punctured with a 25 -gauge needle and $300-500 \mu$ lof blood was collected into heparinized tubes. The blood was transferred into centrifuge tubes and centrifuged at $7000 \mathrm{rpm}$ for 15 $\mathrm{min}$. The plasma was removed and stored in vials at $-70^{\circ} \mathrm{C}$ until assayed for T. Plasma $\mathrm{T}$ concentrations were quantified by radioimmunoassay (RIA) using a commercial double antibody system purchased from MP Biomedicals. For extraction, $500 \mu \mathrm{l}$ of a 50/50 mixture of cyclohexane/ ethylacetate was added to $50 \mu \mathrm{l}$ of plasma and the tubes were incubated for $10 \mathrm{~min}$ with continuous shaking. After centrifugation, the tubes were placed in a mixture of dry ice and ethanol for snap freezing, followed by transfer of the organic phase to a new tube. After thawing, samples were reextracted following the same method. The combined supernatants were dried by vacuum centrifugation and stored at $-20^{\circ} \mathrm{C}$ until further analysis. For T measurements, the dried samples were dissolved in $25 \mu \mathrm{l}$ of steroid diluent buffer and further treated following the protocol of the RIA kit. Testosterone standards ranged from $0.1 \mathrm{ng} / \mathrm{ml}$ to $10 \mathrm{ng} / \mathrm{ml}$ but the effective detection limit could be extended to $0.05 \mathrm{ng} / \mathrm{ml}$ owing to the concentration effect of the extraction procedure. The intra-assay coefficient of variation was $4.6-9.1 \%$ (medium-low/high concentrations) and all samples were run in a single assay.

Regions of interest. Considering that the FA-maps show the sharpest neuroanatomical contrast in the starling brain (De Groof et al., 2006), regions of interest (ROIs) were delineated on these maps (Fig. 1) using AMIRA software (Amira; Visage Imaging). ROIs were delineated for each individual subject blindly (unaware of season) by one researcher. The nomenclature used in the present paper is based on the recently revised nomenclature for the avian brain (Reiner et al., 2004).

The song control system (SCS) contains a number of nuclei that are organized into two pathways. Both pathways start from the nucleus HVC (used as the proper name) (Alvarez-Buylla et al., 1990; Tramontin and Brenowitz, 1999). The main descending "motor pathway" is essential for song production and includes the robust nucleus of the arcopallium (RA). The "anterior forebrain pathway" (AFP), which includes Area X, is essential for song learning and for song maintenance (Brainard and Doupe, 2000). Two song control nuclei, RA and Area X, in the right (imaged) hemisphere, and the right telencephalon were delineated on the multislice images collected in April and July by manually segmenting these structures on the FA-map of each subject using Amira software (Visage Imaging). HVC could not be delineated accurately with the applied DTI method due to a lack of contrast.

The caudomedial nidopallium (NCM), the secondary auditory region responsible for song discrimination (Mello et al., 1995; Bailey et al., 2002; Gentner, 2004; Van Meir et al., 2005; Boumans et al., 2007a,b; Voss et al., 2007), was delineated using field $L$ as rostral border, the cerebellum as caudal border and the lateral ventricle as ventral and dorsal border (Fig. $1 C$ ). The boundaries of NCM in the lateral direction are unknown. We included in our ROI three slices of $0.4 \mathrm{~mm}$ thickness starting at $0.4 \mathrm{~mm}$ from the midline and ending at $1.6 \mathrm{~mm}$ from the midline. These lateral boundaries incorporate the NCM as defined in previous experiments on starlings (Gentner et al., 2004; Van Meir et al., 2005; George et al., 2008). This ROI did not incorporate HVC which is known to display a pronounced seasonal change in volume and which is located between 2.5 and $3.2 \mathrm{~mm}$ from the midline in a starling (George et al., 2005; Van Meir et al., 2006). Due to the fixed width of $1.2 \mathrm{~mm}$ (medial-lateral) of the NCM ROI, medial-lateral volume change could not be studied, limiting our 


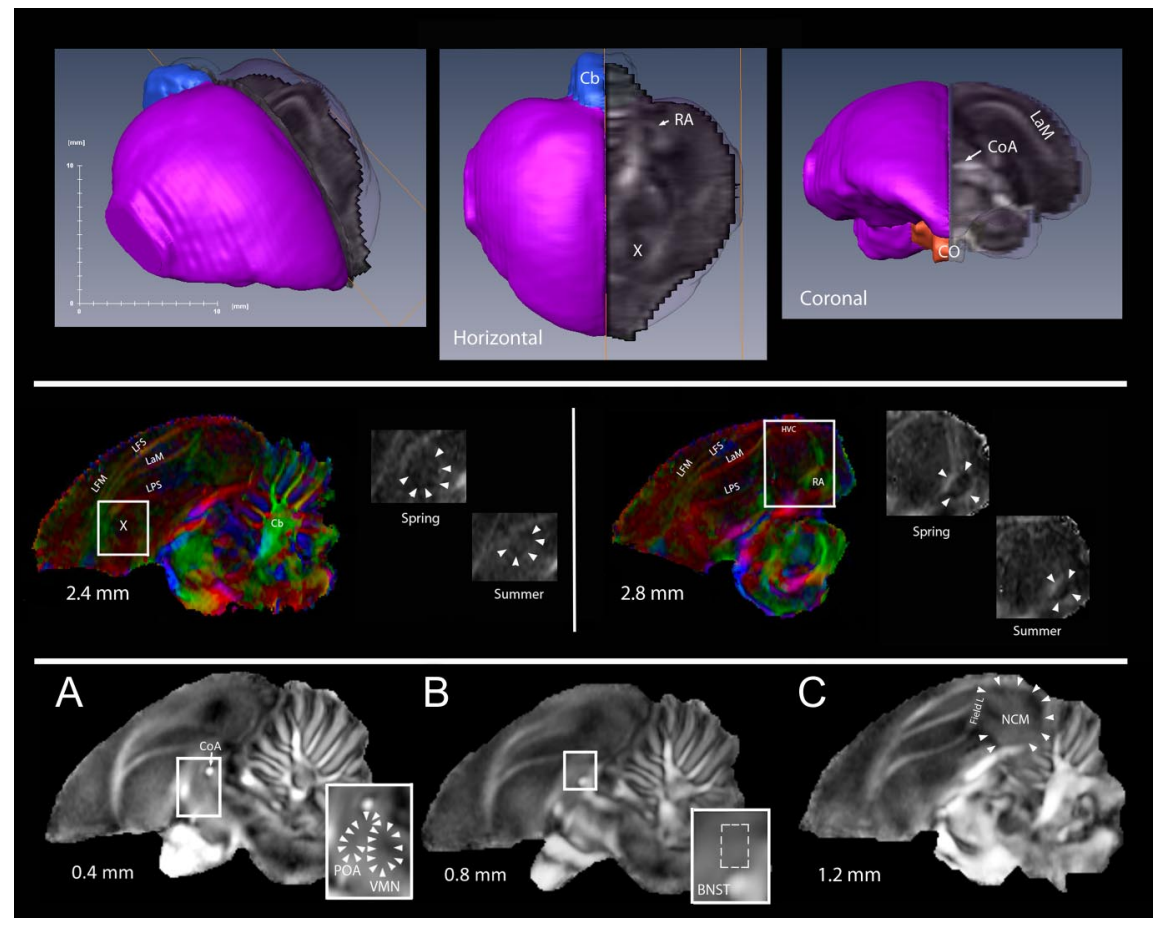

Figure 1. Regions of interest. Top, Three-dimensional rendering of the starling brain. The right hemisphere is a surface rendering of the telencephalon (pink), the cerebellum (blue, (b), and the Optic chiasm (orange, $(0)$. The left hemisphere is a transparent mirror image of the right hemisphere with horizontal and coronal FA maps projected into it. Middle, Two sagittal color coded FA maps (right is caudal) of one male starling in the breeding season. The colors define the main diffusion direction in each voxel (red: rostral-caudal; green: dorsal-ventral; blue: medial-lateral). The insets show Area $X$ and RA respectively of the same subject at the two different seasons. Bottom, Representative slices of FA-maps on which the regions of interest (insets) are depicted. $\boldsymbol{A}$, POA and VMN of the SBN. B, BNST of the SBN. $\boldsymbol{C}$, Auditory region NCM. Regions of interest expand more than the depicted slices; see Materials and Methods for more detailed information. $C b$, Cerebellum; COA, commissura anterior; $C 0$, optic chiasm; Field L, used as proper name; LFM, lamina frontalis suprema; LFS, lamina frontalis superior; LPS, lamina pallio-subpallialis; LaM, lamina mesopallialis; X, Area X.
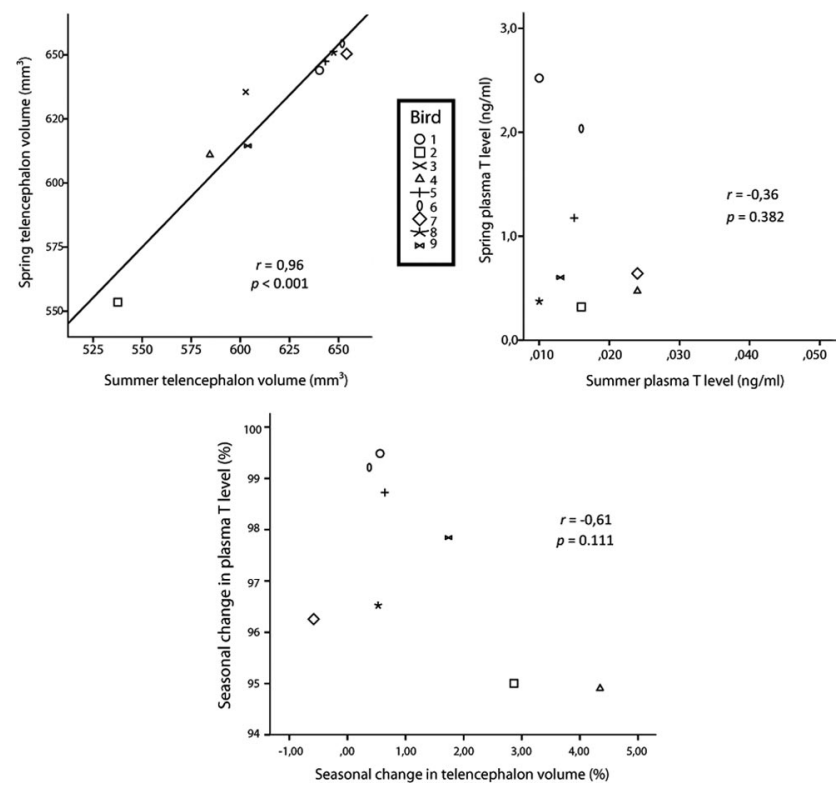

Figure 2. Seasonal changes of telencephalon volume $(N=9)$ and plasma T values $(N=8)$. Top, Scatterplot of individual telencephalon volumes (left) and plasma testosterone levels (right) in breeding (spring) versus nonbreeding season (summer). The correlation between seasons is significant for the telencephalon volume but not for the plasma testosterone level. Bottom, Scatterplot of individual telencephalon volume changes versus individual plasma testosterone level changes. investigation to potential rostral-caudal and dorsal-ventral volume changes.

The SBN (Metzdorf et al., 1999; Soma et al., 2003) has been directly implicated in the regulation of singing behavior in songbirds (Heimovics and Riters, 2005, 2006). Due to the high risk of partial volume effect in the Nucleus taeniae of the amygdala (TnA, a nucleus of the SBN surrounded by white matter and cerebrospinal fluid) it was decided not to incorporate this nucleus into our analysis. The ROI for the nuclei of the SBN were as follows.

Preoptic area (POA) was identified on a slice positioned $0.4 \mathrm{~mm}$ lateral from the midsagittal plane. It was delineated as a long diagonally shaped area with its dorsal border delimited by the commisura anterior ( $\mathrm{CoA}$ ) and the ventral border delimited by the tractus septopalliomesencephalicus (Fig. 1A).

The bed nucleus of the stria terminalis (BNST) was identified on slices laterally positioned at 0.8 and $1.2 \mathrm{~mm}$ from the midsagittal plane. Because no boundaries can be detected on the images, the ROI was defined as a rectangle $\left(0.196 \times 0.294 \mathrm{~mm}^{2}\right)$ dorsal to the CoA and the fasciculus prosencephali lateralis (Fig. $1 B$ ) to be sure that it encompasses BNST.

Nucleus ventromedialis hypothalami (VMN) was delineated on a slice laterally positioned at $0.4 \mathrm{~mm}$ from the midline and dorsally to the optic chiasm. This region was referred as the nucleus medialis hypothalami posterioris/nucleus lateralis hypothalami posterioris in past work (Metzdorf et al., 1999) (Fig. 1A).

Data analysis. The volumes of the right telencephalon, RA, Area X, and NCM could be calculated from the voxel size $(0.098 \times 0.098 \times$ $0.40 \mathrm{~mm}^{3}$ ) and the number of voxels of the ROI. Due to their relatively small size (sometimes encompassing only one slice), the volumes of the SBN regions could not be accurately defined.

For each ROI we obtained mean and SD of all estimated MRI parameters (FA, MD, $\lambda_{1}, \lambda_{2}, \lambda_{3}$ and $\mathrm{T}_{2}$ ) using AMIRA software (Amira; Visage Imaging).

Statistical analyses. The MRI data were analyzed by repeated measure two-way analyses of variance (ANOVA) with two repeated factors (seasons and regions) using SPSS 16.0 (SPSS). When appropriate, these analyses were followed by post hoc testing using the $t$ tests for matched samples corrected for multiple comparisons by the Bonferroni method. Plasma testosterone values and telencephalon volume data were analyzed by paired samples $t$ tests. Relationships between individual differences in volume, DTI parameters, $\mathrm{T}_{2}$ values and plasma $\mathrm{T}$ values were analyzed with the Pearson product moment correlation coefficient $(r)$. Differences and correlations were considered significant for an $\alpha$ level of $p<0.05$.

\section{Results}

\section{Plasma testosterone concentrations}

Beaks of all males were entirely yellow in spring indicating elevated levels of testosterone but had grown entirely black in summer indicative of basal levels of testosterone. In agreement with this, T plasma values were found to be significantly higher in spring compared to summer (mean $\pm \mathrm{SD}$ : spring: $1.02 \pm 0.83$ $\mathrm{ng} / \mathrm{ml}$; summer: $0.02 \pm 0.01 \mathrm{ng} / \mathrm{ml}$; paired $t$ test: $t=3.40, p=$ $0.011)$. One subject displayed an extremely small change between seasons and was identified as an outlier (bird \#3) and therefore removed from subsequent tests. The plasma $\mathrm{T}$ level did not show a significant correlation between the two seasons $(r=-0.36, p=$ 0.382 ) (Fig. 2), i.e., knowing the plasma T level of a bird in spring 
does not allow to predict its $\mathrm{T}$ level in summer.

\section{Telencephalon volume changes}

A paired $t$ test revealed a larger volume for the telencephalon during the spring (breeding season) compared to the summer (nonbreeding season) (spring: $629.07 \pm$ $32.46 \mathrm{~mm}^{3}$; summer: $618.42 \pm 39.51 \mathrm{~mm}^{3}$; $t=2.62, p=0.031)$. This volume decrease from spring to summer (mean change $=$ $\left[100 \times\right.$ (volume $_{\text {spring }}-$ volume $\left._{\text {summer }}\right) /$ volume $\left._{\text {spring }}\right]=1.7 \%$; coefficient of variation: $\mathrm{CV}=1.1)$ was quite prominent in some subjects (maximum observed: 5.2\%) but more limited in others (minimum $0.4 \%$ ).

The telencephalon volume showed a significant positive correlation between the two seasons $(r=0.96, p<0.001)$ (Fig. 2 ), i.e., knowing the telencephalon volume of a bird in spring allows to predict this volume in summer. To test whether plasma $\mathrm{T}$ has an influence on the seasonal volume changes we performed a linear regression with "volume changes" as dependent and "plasma T value changes" as independent variable. No significant correlation was found between these two variables $(r=-0.61 ; p=0.111)$ (Fig. 2).

\section{Song control nuclei and auditory \\ NCM volumes}

Since we observed a significant change in telencephalon volume between seasons, the following volumes are always expressed as percentages relative to the total telencephalon volume. One outlier value was found for the relative volume of Area $\mathrm{X}$ and this subject (bird \#1, different to the plasma $\mathrm{T}$ outlier) was removed from the subsequent tests. A repeated measures $2 \times$ 3 ANOVA (two seasons $\times$ three ROI: RA, Area $\mathrm{X}$ and $\mathrm{NCM}$ ) on volume data revealed a significant main season effect consisting of a decrease from spring to summer $\left(F_{(1,7)}=44.65, p<0.001\right)$ (Fig. 3) as well as a significant main region effect $\left(F_{(1,7)}=818.56, p<0.001\right)$. The interaction (season ${ }^{\star}$ region) showed no significant effect $\left(F_{(1,7)}=3.16, p=\right.$ $0.112)$.

None of the volumes showed a significant correlation between the two seasons (RA: $r=-0.46, p=0.216$; Area X: $r=0.39, p=$ 0.336; NCM: $r=0.39, p=0.299$ ) (Fig. 3), i.e., knowing the volume of a region in a bird in spring does not allow to predict the volume of this region in summer. The interindividual variability of intraindividual seasonal volume changes was found to be quite high (mean change: $\mathrm{RA}=37 \%$, Area $\mathrm{X}=37 \%$ and $\mathrm{NCM}=6 \%$; CV respectively: $0.48,0.47$ and 1.36 ), allowing to test potential correlation of volume changes between regions. However we did not find any significant correlation between the regions, meaning that the amplitude of volume changes within one bird was not consistent between regions (NCM/RA: $r=0.492, p=0.179$; $\mathrm{NCM} /$ Area $\mathrm{X}: r=-0.470, p=0.240$; RA/Area X: $r=-0.087$, $p=0.837)$. For instance, the bird presenting the maximum vol-

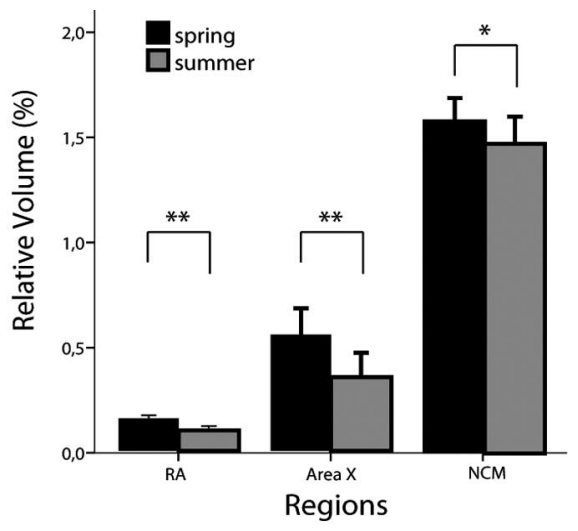

RA

Area X

NCM

Figure 3. Seasonal changes of RA $(N=9)$, Area $X(N=8)$, and NCM $(N=9)$ volumes. Top, Mean seasonal changes of RA, Area $X$, and NCM volumes. Error bars correspond to SDs. $\left({ }^{*} p<0.0{ }^{* *} p<0.01\right.$ ). Middle, Scatterplot of individual volumes (RA, Area $X$ , the volumes of RA, Area $X$, and NCM are expressed relative to the volume of the right telencephalon hemisphere (in \%).

RA
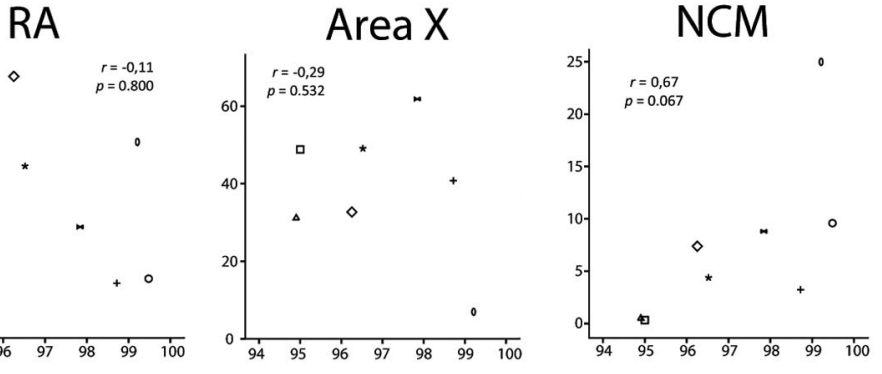

Seasonal change in plasma T level (\%)

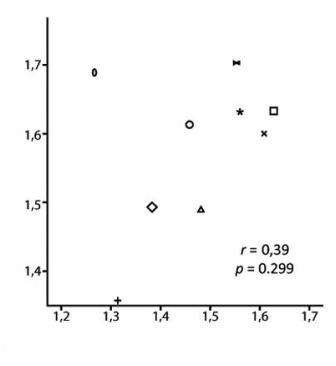

Summer relative volume (\%)

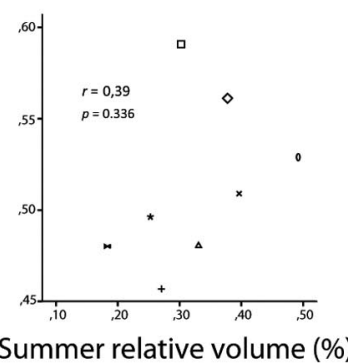

ume change of RA compared to other birds, presented a medium volume change of Area X and NCM (bird \#7 in Fig. 3).

Finally, no significant correlation was found between $\mathrm{T}$ level changes and volume changes in any region (RA: $r=-0.11 ; p=$ 0.800 ; Area X: $r=-0.23$; $p=0.532$; NCM: $r=0.67 ; p=0.067$ ) (Fig. 3).

\section{Diffusion tensor imaging findings}

A $2 \times 6$ repeated-measures ANOVA which tested for seasonal effect on FA values in all six ROIs (RA, Area X, NCM, POA, $\mathrm{VMN}$, and BNST) revealed a significant main seasonal effect consisting in a decrease in summer $\left(F_{(1,6)}=12.23, p=0.013\right)$ (Fig. 4) as well as a main ROI effect $\left(F_{(1,6)}=27.83, p<0.001\right)$. The interaction (season ${ }^{\star}$ region) showed a significant effect $\left(F_{(1,6)}=\right.$ 3.85, $p=0.008)$. Post hoc paired $t$ tests revealed a significant difference between spring and summer for FA in RA $(t=3.79$, $p=0.005), \operatorname{NCM}(t=3.72, p=0.007), \operatorname{POA}(t=3.53, p=0.012)$ and VMN $(t=3.47, p=0.013)$ but not in Area X $(t=0.89, p=$ $0.401)$ nor in $\operatorname{BNST}(t=-1.21, p=0.261)$ (Fig. 4$)$. 

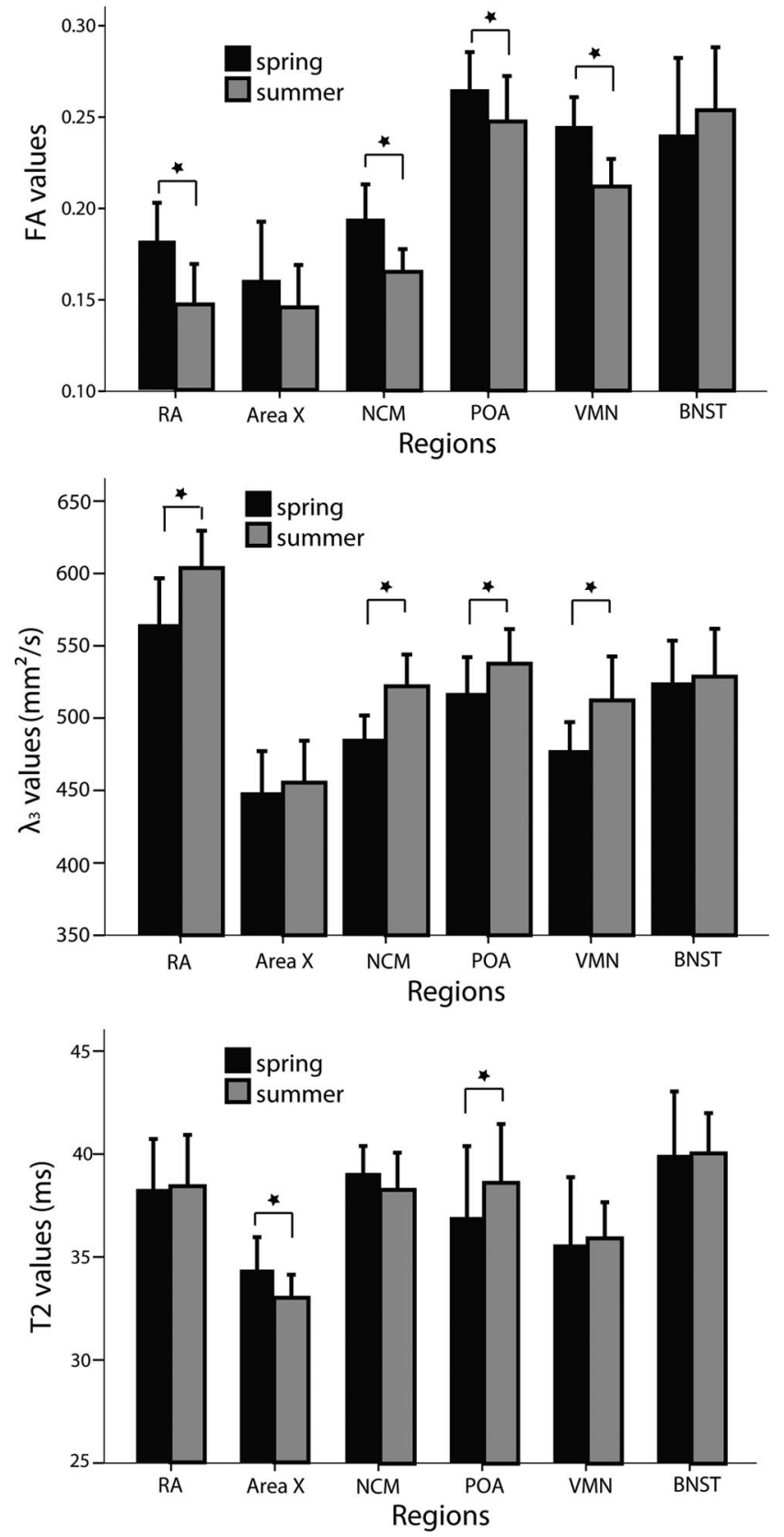

Figure 4. Seasonal changes of $M R I$ values in $\operatorname{RA}(N=9)$, $\operatorname{Area} X(N=8), N C M(N=9)$ and social behavior network nuclei (all $N=9$, except POA, $N=8$ ). Top, Mean seasonal changes of FA values. Error bars correspond to SDs. $\left.{ }^{*} p<0.05\right)$. FA is a dimensionless value between 0 (isotropic) and 1 (fully anisotropic). Middle, Mean seasonal changes $\lambda_{3}$ values. Error bars correspond to SDs. $\left({ }^{*} p<0.05\right)$. Bottom, Mean seasonal changes of $\mathrm{T}_{2}$ values. Error bars correspond to SD. $\left({ }^{*} p \leq 0.05\right)$.

The FA value of POA showed a significant positive correlation ( $r=0.91, p=0.004$ ) between the two seasons, i.e., knowing the FA value in POA of a bird in spring allows to predict this value in summer. For the other regions no significant correlation was observed (RA: $r=0.17, p=0.658$; Area X: $r=-0.60, p=0.088$; NCM: $r=0.06, p=0.892$; VMN: $r=-0.35, p=0.444$; BNST: $r=0.63, p=0.072$ ). We did not find any significant correlation of intraindividual FA changes between ROI, meaning that the amplitude of FA changes within one bird was not consistent between ROI (NCM/POA: $r=0.17, p=0.715$; NCM/VMN: $r=$ $-0.07, p=0.88$; NCM/RA: $r=0.21, p=0.622$; POA/VMN: $r=$
0.73, $p=0.064$; POA/RA: $r=-0.15, p=0.757$; VMN/RA: $r=$ $-0.54, p=0.210)$. To test whether plasma T has an influence on the seasonal FA changes, we performed a new linear regression with "FA changes" as dependent and "plasma T value changes" as independent variable. No significant correlation was found between these two variables in any region (RA: $r=-0.27 ; p=$ 0.521 ;CM: $r=0.37 ; p=0.418$; POA: $r=0.29 ; p=0.582$; VMN: $r=-0.16 ; p=0.762$ ).

A $2 \times 6$ repeated-measures ANOVA which tested for seasonal differences for MD in all six ROIs revealed a significant mean region effect $\left(F_{(1,6)}=124.88, p<0.001\right)$ but no significant main seasonal effect $\left(F_{(1,6)}=3.99, p=0.093\right)$. The interaction (season*region) showed a significant effect $\left(F_{(1,6)}=2.81\right.$, $p=0.034)$. Post hoc paired $t$ tests for the six ROIs revealed no significant seasonal effect for MD in any region (RA: $t=-1.46$, $p=0.182$; Area X: $t=0.10, p=0.926$; NCM: $t=-2.20, p=$ 0.064; POA: $t=-2.25, p=0.060$; VMN: $t=1.96, p=0.097$; BNST: $t=-0.84, p=0.423)$. The observed significant interaction can be explained by the opposite direction of nonsignificant trends observed in NCM and POA versus VMN.

To investigate which DTI eigenvalue(s) was (were) responsible for the seasonal FA differences, a $2 \times 6$ repeated-measures ANOVA was run for each of the three eigenvalues. It revealed no significant seasonal main effect for $\lambda_{1}\left(F_{(1,6)}=2.30, p=0.180\right)$ or for $\lambda_{2}\left(F_{(1,6)}=3.89, p=0.096\right)$. For $\lambda_{3}$ however a significant seasonal increase from spring to summer was found $\left(F_{(1,6)}=\right.$ 9.12, $p=0.023$ ) (Fig. 4). The interaction (season ${ }^{\star}$ region) also showed a significant effect $\left(F_{(1,6)}=3.72, p=0.040\right)$. Post hoc paired $t$ tests for the six ROIs revealed a significant increase for $\lambda_{3}$ in $\mathrm{RA}(t=-3.84, p=0.005), \mathrm{NCM}(t=-4.51, p=0.003), \mathrm{POA}$ $(t=-2.78, p=0.027)$ and $\operatorname{VMN}(t=-3.95, p=0.008)$ but not in Area X $(t=-0.44, p=0.673)$ nor BNST $(t=-0.35, p=$ 0.738 ) (Fig. 4). Thus all the ROIs that showed a seasonal difference in FA also showed a seasonal difference in $\lambda_{3}$.

None of the regions showed a significant correlation between the two seasons for the $\lambda_{3}$ value, i.e., knowing the $\lambda_{3}$ value of a region in bird during spring does not allow to predict this value during summer (RA: $r=0.46, p=0.216$; Area X: $r=-0.29, p=$ 0.445 ; NCM: $r=0.37, p=0.369$; POA: $r=0.65, p=0.082$; VMN: $r=0.65, p=0.112$; BNST: $r=0.35, p=0.359)$. When testing potential correlation of $\lambda_{3}$ changes between ROI, a significant positive correlation was found between intraindividual $\lambda_{3}$ changes of POA and RA ( $r=0.78, p=0.022)$ (Fig. 5) meaning that birds presenting a large $\lambda_{3}$ change in POA also present a large $\lambda_{3}$ change in RA. We did not find any significant correlation of $\lambda_{3}$ changes between other ROI (NCM/POA: $r=0.19, p=0.685$; $\mathrm{NCM} / \mathrm{VMN}: r=0.50, p=0.249$; NCM/RA: $r=0.53, p=0.179$; POA/VMN: $r=0.59, p=0.162$; VMN/RA: $r=0.50, p=0.258)$. Finally, no significant correlation was found between $\mathrm{T}$ level changes and $\lambda_{3}$ changes in any seasonally changing region (RA: $r=-0.20 ; p=0.643$; NCM: $r=-0.16 ; p=0.739$; POA: $r=$ $-0.56 ; p=0.189 ; \mathrm{VMN}: r=-0.06 ; p=0.912)$.

\section{$\mathrm{T}_{2}$ findings}

To see whether a change of water content (osmolarity) is responsible for any of the observed seasonal differences, we performed a $2 \times 6$ repeated-measures ANOVA which tested for seasonal differences for $\mathrm{T}_{2}$ values in all six ROIs. It revealed a significant mean region effect $\left(F_{(1,5)}=18.20, p<0.001\right)$ but no significant main seasonal effect $\left(F_{(1,5)}=0.038, p=0.856\right)$. The interaction (season ${ }^{\star}$ region) showed a significant effect $\left(F_{(1,5)}=3.328, p=\right.$ $0.024)$. Post hoc paired $t$ tests for the six ROIs revealed a significant seasonal effect for $\mathrm{T}_{2}$ in Area $\mathrm{X}(t=4.14, p=0.004)$ consisting of a 
decrease in summer and a trend for $\mathrm{T}_{2}$ in POA $(t=-2.43, p=0.051)$ consisting of an increase in summer (Fig. 4). The other regions did not show any significant differences between seasons (RA: $t=-0.15$, $p=0.882$; NCM: $t=1.0, p=0.358$; VMN: $t=-0.33, p=0.751$; BNST: $t=$ $-0.08, p=0.942)$.

The $\mathrm{T}_{2}$ value of Area $\mathrm{X}$ showed a significant positive correlation between the two seasons $(r=0.81, p=0.015)$, i.e., knowing the $\mathrm{T}_{2}$ value in Area $\mathrm{X}$ of a bird in spring allows to predict this value in summer. This was not the case for POA $(r=$ 0.53, $p=0.227)$. A significant positive correlation of intraindividual $\mathrm{T}_{2}$ changes between Area X and POA was found $(r=$ 0.86, $p=0.028$ ) (Fig. 5), meaning that birds presenting a large $\mathrm{T}_{2}$ change in POA would present a small $\mathrm{T}_{2}$ change in Area X. Possible influence of plasma $\mathrm{T}$ on the seasonal $\mathrm{T}_{2}$ effect was also tested using a linear regression with " $\mathrm{T}_{2}$ changes" as dependent and "plasma $\mathrm{T}$ value changes" as independent variable. No significant linear correlation was found between these two variables for POA $(r=0.73$; $p=0.063)$ or for Area X $(r=0.60 ; p=0.154)$.

\section{Relationships between MRI and volumetric measures}

On the basis of the significant seasonal FA (and $\lambda_{3}$ ) difference in both RA and NCM and a seasonal difference in RA and NCM volumes, Pearson correlations were computed to examine the potential relationship between these variables. No significant correlations were observed between RA volume changes and FA changes $(r=-0.06 ; p=0.869)$ or between RA volume changes and $\lambda_{3}$ changes $(r=0.20 ; p=0.600)$. NCM volume changes were not significantly correlated to FA changes $(r=-0.34 ; p=0.411)$ and $\lambda_{3}$ changes $(r=-0.27 ; p=0.520)$.

On the basis of the significant seasonal $\mathrm{T}_{2}$ difference in Area $\mathrm{X}$ and a seasonal difference in Area X volume, Pearson correlation was computed to examine the potential relationship between these variables. The correlation was found to be not significant $(r=-0.26, p=0.569)$.

\section{Discussion}

We have demonstrated by means of DTI that the songbird brain exhibits an extreme seasonal plasticity not merely limited to the SCS. Specifically, we have (1) shown seasonal changes in telencephalon volume, (2) revealed for the first time structural seasonal changes in a secondary auditory region of the telencephalon, namely $\mathrm{NCM}$, (3) detected seasonal changes of cellular attributes in regions involved in social behavior, and finally, (4) observed a relationship between plasticity of the POA and plasticity of nuclei of the SCS.

\section{Seasonal changes of telencephalic volume}

We detected a significant decrease in telencephalon volume in starlings between breeding and nonbreeding conditions. The telencephalon size of songbirds in different seasons has already been reported (Smith, 1996; Brenowitz et al., 1998) but without significant differences. Because it allows to search for volume changes at the intraindividual level, repeated measures MRI is statistically more powerful than histology for identifying small but real differences in volumes, explaining why other studies may have failed to identify this telencephalon volume change. This hypothesis is supported by a meta-analysis study of several experiments where the seasonal change in telencephalon volume became statistically significant when multiple studies were pooled (Smulders, 2002).

Although neurogenesis in the songbird brain is relatively high, seasonal variation of this mechanism has not been observed (except for HVC) (Alvarez-Buylla et al., 1994). Brain size reduction may be achieved via several complementary mechanisms, e.g., changes in the volume of neuropil, cell bodies and/or extracellular space. Seasonal oscillations in brain weight have also been found in mammalian species like Meadow voles (Microtus pennsylvanicus) (Dark et al., 1990) and Sorex shrews (Lipotyphla sp), the brain weight of the latter changing 10-30\% seasonally (Dehnel, 1949). Similarly to songbirds, these changes were not due to changes in brain cell number (Bartkowska et al., 2008).

\section{Seasonal changes in the song control system}

The seasonal volumetric changes of Area X and RA observed here at the individual level have the same amplitude as those found in free ranging male starlings (Riters et al., 2002), confirming previous histological studies. Although plasma T values and RA and Area $\mathrm{X}$ volumes show a decrease at the group level between the breeding and the nonbreeding season, no correlation was found at the individual level between these variables. Many attempts to explain individual variation in singing behavior or its neural substrates as a function of variation in plasma steroid concentrations have failed (see Adkins-Regan, 2005; Ball and Balthazart, 2008 for review). This lack of correlation could possibly be explained by the "Multiple Threshold Hypothesis" (Hews and Moore, 1997): due to the existence of individual thresholds for androgens, the accumulation of individual variations in threshold would provide the impression of a correlation at the population level, but this correlation would in fact not exist in any single subject. Alternatively these results could indicate that $\mathrm{T}$ is not the only factor responsible for song control nuclei seasonal plasticity and in starlings song output has been proposed as an alternative determinant factor (Sartor and Ball, 2005). Starlings are known to sing all year long, except during molt when song rates decrease or birds do not sing at all (Eens, 1997). Since DTI measurements during the nonreproductive season were performed during the molting period, a change in song output may be responsible of the volume changes observed in the present study. Photoperiod changes have also been shown to induce volume changes in song nuclei in starlings (Bernard and Ball, 1997). In European starlings, day length influences the levels and patterns of secretion of T but also 
of other hormones (Dawson and Goldsmith, 1984; Dawson and King, 1994).

The volume change in Area X during the breeding season in song sparrows can be attributed to a change in neuron size and spacing (Thompson and Brenowitz, 2005). This increased spacing between cells and larger neuron size is coherent with the higher $\mathrm{T}_{2}$ we observed in starling during the breeding season. However the lack of significant correlation between volume of Area $\mathrm{X}$ and its $\mathrm{T}_{2}$ value indicates that this mechanism is not sufficient to explain volume changes of Area X and suggests that additional mechanisms are involved.

Volume changes of RA have been shown to consist of an increase in synaptic traits and soma size (Tramontin et al., 1998). These cellular changes may alter the diffusion of water protons (Schoeniger et al., 1994; Szafer et al., 1995), which would explain the seasonal effect on the $\lambda_{3}$ parameter observed in the present study.

\section{Seasonal changes in the auditory telencephalon (NCM)}

As in other songbirds, the secondary auditory region NCM in starlings is responsible for auditory discrimination and song recognition memories (Gentner et al., 2004). Song production and consecutively the auditory environment of starlings change seasonally (Eens, 1997). Seasonal variation in peripheral and brainstem auditory activity in several songbirds has also been observed (Lucas et al., 2002, 2007). Tuning width to simple tone stimuli of NCM neurons in canaries also showed a seasonal variation (Terleph et al., 2008). Here we show for the first time a seasonal effect on NCM at the structural level, consisting on a seasonal change in volume and in the diffusion parameter $\lambda_{3}$. A large population of NCM neurons in zebra finches expresses aromatase (Saldanha et al., 2000), an enzyme that converts androgens into estrogens (Balthazart et al., 2003). Expression of aromatase in seasonal breeding canaries varies with seasons, being higher during the breeding season (Fusani et al., 2000). Aromatase positive neurons have highly complex branching patterns and large nuclei (Saldanha et al., 2000), two factors that influence the diffusion of water protons of tissues (Schoeniger et al., 1994; Szafer et al., 1995). Even if these results have been observed in other songbirds, they may explain the changes of NCM diffusion parameter $\lambda_{3}$ we observed in starlings. For this reason, we hypothesize that some DTI parameters (especially $\lambda_{3}$ ) may be considered as indirect markers of aromatase activity.

It has been shown in starlings that the responsiveness to song changes as a function of day length (Calhoun et al., 1993). An increased volume of an auditory region in spring may thus be an indication of increased auditory sensitivity at that time, possibly aiding in the perception of vocal signals. Sexual competition (Eens, 1997) may be the driving force increasing starling acoustic sensitivity in the spring.

\section{Seasonal changes in the "social behavior network"}

Most research on neural control of singing has focused exclusively on the SCS, without reference to how this system might interact with the SBN, involved in the anticipation of sexual behavior and the motivation to sing (Riters and Ball, 1999; Maney and Ball, 2003; Heimovics et al., 2009). Since these two functions vary seasonally, one might expect seasonal plasticity in this network. The present study revealed seasonal plasticity in POA (in terms of $\lambda_{3}$ and $T_{2}$ values) but also in VMN (in terms of $\lambda_{3}$ ). Numerous studies have shown the importance of aromatase for the regulation of sexual and aggressive behaviors of starlings and other birds during the reproductive season, particularly in brain areas such as POA and VMN (Riters et al., 2000; Ball and Balthazart,
2004). The presence of statistically significant changes of $\lambda_{3}$ between seasons in brain regions that display seasonal changes in aromatase activity supports our hypothesis of $\lambda_{3}$ being a possible marker of aromatase activity.

Indirect neuro-anatomical connections between POA and the SCS have been found in starlings. POA sends projections to area ventralis of Tsai (VTA) (Riters and Alger, 2004) and VTA has been found to project to RA, HVC and Area X (Appeltants et al., 2000). Both for POA and VTA a positive relationship was found between total amount of song sung and cFOS-labeled cells, but only for starlings singing during, and not outside, a breeding context (Heimovics and Riters, 2005). Furthermore it was suggested that in starlings POA stimulates vocal communication in a sexually relevant context, but inhibits vocal communication outside such a context (Alger and Riters, 2006). In our study we go one step further, investigating the individual seasonal plasticity of POA compared to plasticity of song control nuclei. We demonstrated that both Area X and RA plasticity are positively linked with POA plasticity. This result contributes to a growing body of research that highlights the major role of POA in providing contextual input to the SCS.

To the best of our knowledge, our findings provide the first description of structural seasonal changes in an auditory processing region in a vertebrate species. Previously we had already detected unknown seasonal changes in white matter (De Groof et al., 2008). Together, these results extend our views on a seasonally dynamic avian brain (Nottebohm, 1981; Tramontin and Brenowitz, 2000; Ball et al., 2002; Brenowitz, 2004), which not only hones its SCS but also its sensory and social systems to be prepared for the breeding season.

\section{References}

Adkins-Regan E (2005) Hormones and animal social behavior. Princeton, NJ: Princeton UP.

Alger SJ, Riters LV (2006) Lesions to the medial preoptic nucleus differentially affect singing and nest box-directed behaviors within and outside of the breeding season in European starlings (Sturnus vulgaris). Behav Neurosci 120:1326-1336.

Alvarez-Buylla A, Kirn JR, Nottebohm F (1990) Birth of projection neurons in adult avian brain may be related to perceptual or motor learning. Science 249:1444-1446.

Alvarez-Buylla A, Ling CY, Yu WS (1994) Contribution of neurons born during embryonic, juvenile, and adult life to the brain of adult canaries: regional specificity and delayed birth of neurons in the song-control nuclei. J Comp Neurol 347:233-248.

Appeltants D, Absil P, Balthazart J, Ball GF (2000) Identification of the origin of catecholaminergic inputs to HVc in canaries by retrograde tract tracing combined with tyrosine hydroxylase immunocytochemistry. J Chem Neuroanat 18:117-133.

Bailey DJ, Rosebush JC, Wade J (2002) The hippocampus and caudomedial neostriatum show selective responsiveness to conspecific song in the female zebra finch. J Neurobiol 52:43-51.

Ball GF, Balthazart J (2004) Hormonal regulation of brain circuits mediating male sexual behavior in birds. Physiol Behav 83:329-346.

Ball GF, Balthazart J (2008) Individual variation and the endocrine regulation of behaviour and physiology in birds: a cellular/molecular perspective. Philos Trans R Soc Lond B Biol Sci 363:1699-1710.

Ball GF, Wingfield JC (1987) Changes in plasma-levels of luteinizinghormone and sex steroid-hormone in relation to multiple-broodedness and nest-site density in male starlings. Physiol Zool 60:191-199.

Ball GF, Riters LV, Balthazart J (2002) Neuroendocrinology of song behavior and avian brain plasticity: multiple sites of action of sex steroid hormones. Front Neuroendocrinol 23:137-178.

Balthazart J, Baillien M, Charlier TD, Cornil CA, Ball GF (2003) Multiple mechanisms control brain aromatase activity at the genomic and nongenomic level. J Steroid Biochem Mol Biol 86:367-379.

Bartkowska K, Djavadian RL, Taylor JR, Turlejski K (2008) Generation re- 
cruitment and death of brain cells throughout the life cycle of Sorex shrews (Lipotyphla). Eur J Neurosci 27:1710-1721.

Basser PJ, Mattiello J, LeBihan D (1994) MR diffusion tensor spectroscopy and imaging. Biophys J 66:259-267.

Beaulieu C (2002) The basis of anisotropic water diffusion in the nervous system-a technical review. NMR Biomed 15:435-455.

Bernard DJ, Ball GF (1997) Photoperiodic condition modulates the effects of testosterone on song control nuclei volumes in male European starlings. Gen Comp Endocrinol 105:276-283.

Bhagat YA, Beaulieu C (2004) Diffusion anisotropy in subcortical white matter and cortical gray matter: changes with aging and the role of CSFsuppression. J Magn Reson Imaging 20:216-227.

Boumans T, Theunissen FE, Poirier C, Van Der Linden A (2007a) Neural representation of spectral and temporal features of song in the auditory forebrain of zebra finches as revealed by functional MRI. Eur J Neurosci 26:2613-2626.

Boumans T, Vignal C, Smolders A, Sijbers J, Verhoye M, Van Audekerke J, Mathevon N, Van der Linden A (2007b) Functional magnetic resonance imaging in zebra finch discerns the neural substrate involved in segregation of conspecific song from background noise. J Neurophysiol 99:931-938.

Brainard MS, Doupe AJ (2000) Auditory feedback in learning and maintenance of vocal behaviour. Nat Rev Neurosci 1:31-40.

Brenowitz EA (2004) Plasticity of the adult avian song control system. Ann N Y Acad Sci 1016:560-585.

Brenowitz EA, Baptista LF, Lent K, Wingfield JC (1998) Seasonal plasticity of the song control system in wild Nuttall's white-crowned sparrows. J Neurobiol 34:69-82.

Calhoun S, Hulse SH, Braaten RF, Page SC, Nelson RJ (1993) Responsiveness to conspecific and alien song by canaries (Serinus-canaria) and European starlings (Sturnus-vulgaris) as a function of photoperiod. J Comp Psychol 107:235-241.

Dark J, Spears N, Whaling CS, Wade GN, Meyer JS, Zucker I (1990) Long day lengths promote brain growth in meadow voles. Brain Res Dev Brain Res 53:264-269.

Dawson A (1983) Plasma gonadal steroid levels in wild starlings (Sturnus vulgaris) during the annual cycle and in relation to the stages of breeding. Gen Comp Endocrinol 49:286-294.

Dawson A, Goldsmith AR (1984) Effects of gonadectomy on seasonal changes in plasma LH and prolactin concentrations in male and female starlings (Sturnus vulgaris). J Endocrinol 100:213-218.

Dawson A, King V (1994) Thyroidectomy does not affect the daily or freerunning rhythms of plasma melatonin in European starlings. J Biol Rhythms 9:137-144.

De Groof G, Verhoye M, Van Meir V, Tindemans I, Leemans A, Van der Linden A (2006) In vivo diffusion tensor imaging (DTI) of brain subdivisions and vocal pathways in songbirds. Neuroimage 29:754-763.

De Groof G, Verhoye M, Van Meir V, Balthazart J, Van der Linden A (2008) Seasonal rewiring of the songbird brain: an in vivo MRI study. Eur J Neurosci 28:2475-2485.

Dehnel A (1949) Studies on the genus Sorex L. Ann. Univ. M. Curie-Sklod., 4:18-102.

De Ridder E, Pinxten R, Mees V, Eens M (2002) Short- and long-term effects of male-like concentrations of testosterone on female European starlings (Sturnus vulgaris). AUK 119:487-497.

Eens M (1997) Understanding the complex song of the European starling: an integrated ethological approach. Adv Study Anim Behav 26:355-434.

Fusani L, Van't Hof T, Hutchison JB, Gahr M (2000) Seasonal expression of androgen receptors, estrogen receptors, and aromatase in the canary brain in relation to circulating androgens and estrogens. J Neurobiol 43:254-268.

Gentner TQ (2004) Neural systems for individual song recognition in adult birds. Ann N Y Acad Sci 1016:282-302.

Gentner TQ, Hulse SH, Ball GF (2004) Functional differences in forebrain auditory regions during learned vocal recognition in songbirds. J Comp Physiol A Neuroethol Sens Neural Behav Physiol 190:1001-1010.

George I, Cousillas H, Richard JP, Hausberger M (2005) Auditory responses in the HVC of anesthetized starlings. Brain Res 1047:245-260.

George I, Cousillas H, Richard JP, Hausberger M (2008) A potential neural substrate for processing functional classes of complex acoustic signals. PLoS ONE 3:e2203.
Goodson JL (2005) The vertebrate social behavior network: evolutionary themes and variations. Horm Behav 48:11-22.

Hasan KM, Halphen C, Kamali A, Nelson FM, Wolinsky JS, Narayana PA (2009) Caudate nuclei volume, diffusion tensor metrics, and $T_{(2)}$ relaxation in healthy adults and relapsing-remitting multiple sclerosis patients: implications for understanding gray matter degeneration. J Magn Reson Imaging 29:70-77.

Hausberger M, Richarddyris MA, Henry L, Lepage L, Schmidt I (1995) Song sharing reflects the social-organization in a captive group of European starlings (Sturnus-vulgaris). J Comp Psychol 109:222-241.

Heimovics SA, Riters LV (2005) Immediate early gene activity in song control nuclei and brain areas regulating motivation relates positively to singing behavior during, but not outside of, a breeding context. J Neurobiol 65:207-224.

Heimovics SA, Riters LV (2006) Breeding-context-dependent relationships between song and cFOS labeling within social behavior brain regions in male European starlings (Sturnus vulgaris). Horm Behav 50:726-735.

Heimovics SA, Riters LV (2007) ZENK labeling within social behavior brain regions reveals breeding context-dependent patterns of neural activity associated with song in male European starlings (Sturnus vulgaris). Behav Brain Res 176:333-343.

Heimovics SA, Cornil CA, Ball GF, Riters LV (2009) D1-like dopamine receptor density in nuclei involved in social behavior correlates with song in a context-dependent fashion in male European starlings. Neuroscience 159:962-973.

Hews DK, Moore MC (1997) Hormones and sex-specific traits: critical questions. In: Parasites and pathogens: effects on host hormones and behavior (Beckage NE, ed), pp 277-292. New York: International Thomas Publisher.

Hultcrantz M, Simonoska R, Stenberg AE (2006) Estrogen and hearing: a summary of recent investigations. Acta Otolaryngol 126:10-14.

Lebel C, Rasmussen C, Wyper K, Walker L, Andrew G, Yager J, Beaulieu C (2008) Brain diffusion abnormalities in children with fetal alcohol spectrum disorder. Alcohol Clin Exp Res 32:1732-1740.

Le Bihan D, Mangin JF, Poupon C, Clark CA, Pappata S, Molko N, Chabriat H (2001) Diffusion tensor imaging: concepts and applications. J Magn Reson Imaging 13:534-546.

Lucas JR, Freeberg TM, Krishnan A, Long GR (2002) A comparative study of avian auditory brainstem responses: correlations with phylogeny and vocal complexity, and seasonal effects. J Comp Physiol A Neuroethol Sens Neural Behav Physiol 188:981-992.

Lucas JR, Freeberg TM, Long GR, Krishnan A (2007) Seasonal variation in avian auditory evoked responses to tones: a comparative analysis of Carolina chickadees, tufted titmice, and white-breasted nuthatches. J Comp Physiol A Neuroethol Sens Neural Behav Physiol 193:201-215.

Maney DL, Ball GF (2003) Fos-like immunoreactivity in catecholaminergic brain nuclei after territorial behavior in free-living song sparrows. J Neurobiol 56:163-170.

Maney DL, Cho E, Goode CT (2006) Estrogen-dependent selectivity of genomic responses to birdsong. Eur J Neurosci 23:1523-1529.

Maney DL, Goode CT, Lange HS, Sanford SE, Solomon BL (2008) Estradiol modulates neural responses to song in a seasonal songbird. J Comp Neurol 511:173-186.

Mello C, Nottebohm F, Clayton D (1995) Repeated exposure to one song leads to a rapid and persistent decline in an immediate early gene's response to that song in zebra finch telencephalon. J Neurosci 15:6919-6925.

Metzdorf R, Gahr M, Fusani L (1999) Distribution of aromatase, estrogen receptor, and androgen receptor mRNA in the forebrain of songbirds and nonsongbirds. J Comp Neurol 407:115-129.

Newman SW (1999) The medial extended amygdala in male reproductive behavior. A node in the mammalian social behavior network. Ann N Y Acad Sci 877:242-257.

Nottebohm F (1981) A brain for all seasons: cyclical anatomical changes in song control nuclei of the canary brain. Science 214:1368-1370.

Pfefferbaum A, Adalsteinsson E, Rohlfing T, Sullivan EV (2008) Diffusion tensor imaging of deep gray matter brain structures: effects of age and iron concentration. Neurobiol Aging. Advance online publication. Retrieved May 29, 2008. doi:10.1016/jneurobiolaging.2008.04.013.

Pierpaoli C, Righini A, Linfante I, Tao-Cheng JH, Alger JR, Di Chiro G (1993) Histopathologic correlates of abnormal water diffusion in cere- 
bral ischemia: diffusion-weighted MR imaging and light and electron microscopic study. Radiology 189:439-448.

Reiner A, Perkel DJ, Bruce LL, Butler AB, Csillag A, Kuenzel W, Medina L, Paxinos G, Shimizu T, Striedter G, Wild M, Ball GF, Durand S, Güntürkün O, Lee DW, Mello CV, Powers A, White SA, Hough G, Kubikova L, et al. (2004) Revised nomenclature for avian telencephalon and some related brainstem nuclei. J Comp Neurol 473:377-414.

Riters LV, Alger SJ (2004) Neuroanatomical evidence for indirect connections between the medial preoptic nucleus and the song control system: possible neural substrates for sexually motivated song. Cell Tissue Res 316:35-44.

Riters LV, Ball GF (1999) Lesions to the medial preoptic area affect singing in the male European starling (Sturnus vulgaris). Horm Behav 36:276-286.

Riters LV, Eens M, Pinxten R, Duffy DL, Balthazart J, Ball GF (2000) Seasonal changes in courtship song and the medial preoptic area in male European starlings (Sturnus vulgaris). Horm Behav 38:250-261.

Riters LV, Eens M, Pinxten R, Ball GF (2002) Seasonal changes in the densities of alpha(2) noradrenergic receptors are inversely related to changes in testosterone and the volumes of song control nuclei in male European starlings. J Comp Neurol 444:63-74.

Saldanha CJ, Tuerk MJ, Kim YH, Fernandes AO, Arnold AP, Schlinger BA (2000) Distribution and regulation of telencephalic aromatase expression in the zebra finch revealed with a specific antibody. J Comp Neurol 423:619-630.

Sartor JJ, Ball GF (2005) Social suppression of song is associated with a reduction in volume of a song-control nucleus in European starlings (Sturnus vulgaris). Behav Neurosci 119:233-244.

Schoeniger JS, Aiken N, Hsu E, Blackband SJ (1994) Relaxation-time and diffusion NMR microscopy of single neurons. J Magn Reson B 103:261-273.

Smith GT (1996) Seasonal plasticity in the song nuclei of wild rufous-sided towhees. Brain Res 734:79-85.

Smulders TV (2002) Natural breeding conditions and artificial increases in testosterone have opposite effects on the brains of adult male songbirds: a meta-analysis. Horm Behav 41:156-169.

Soma KK, Schlinger BA, Wingfield JC, Saldanha CJ (2003) Brain aromatase, 5 alpha-reductase, and 5 beta-reductase change seasonally in wild male song sparrows: relationship to aggressive and sexual behavior. J Neurobiol 56:209-221.

Summers RW, Westlake GE, Feare CJ (1987) Differences in the ages, sexes and physical condition of starlings Sturnus-vulgaris at the center and periphery of roosts. Ibis 129:96-102.

Szafer A, Zhong J, Gore JC (1995) Theoretical model for water diffusion in tissues. Magn Reson Med 33:697-712.

Terleph TA, Lu K, Vicario DS (2008) Response properties of the auditory telencephalon in songbirds change with recent experience and season. PLoS ONE 3:e2854.

Thompson CK, Brenowitz EA (2005) Seasonal change in neuron size and spacing but not neuronal recruitment in a basal ganglia nucleus in the avian song control system. J Comp Neurol 481:276-283.

Tramontin AD, Brenowitz EA (1999) A field study of seasonal neuronal incorporation into the song control system of a songbird that lacks adult song learning. J Neurobiol 40:316-326.

Tramontin AD, Brenowitz EA (2000) Seasonal plasticity in the adult brain. Trends Neurosci 23:251-258.

Tramontin AD, Smith GT, Breuner CW, Brenowitz EA (1998) Seasonal plasticity and sexual dimorphism in the avian song control system: stereological measurement of neuron density and number. J Comp Neurol 396:186-192.

Van Meir V, Verhoye M, Absil P, Eens M, Balthazart J, Van der Linden A (2004) Differential effects of testosterone on neuronal populations and their connections in a sensorimotor brain nucleus controlling song production in songbirds: a manganese enhanced-magnetic resonance imaging study. Neuroimage 21:914-923.

Van Meir V, Boumans T, De Groof G, Van Audekerke J, Smolders A, Scheunders P, Sijbers J, Verhoye M, Balthazart J, Van der Linden A (2005) Spatiotemporal properties of the BOLD response in the songbirds' auditory circuit during a variety of listening tasks. Neuroimage 25:1242-1255.

Van Meir V, Pavlova D, Verhoye M, Pinxten R, Balthazart J, Eens M, Van der Linden A (2006) In vivo MR imaging of the seasonal volumetric and functional plasticity of song control nuclei in relation to song output in a female songbird. Neuroimage 31:981-992.

Voss HU, Tabelow K, Polzehl J, Tchernichovski O, Maul KK, SalgadoCommissariat D, Ballon D, Helekar SA (2007) Functional MRI of the zebra finch brain during song stimulation suggests a lateralized response topography. Proc Natl Acad Sci U S A 104:10667-10672. 